\title{
Acute Intervention During Myocardial Infarction in Patients with Prior Coronary Bypass Surgery
}

\author{
Kevin M. Kavanaugh, MD, and Eric J. Topol, MD
}

$\mathbf{T}$ hrombolytic intervention with or without coronary angioplasty is becoming widely accepted as standard therapy for patients who present early with acute myocardial infarction. Thrombolytic therapy has been shown to improve left ventricular function ${ }^{1}$ and reduce mortality. ${ }^{2}$ Nearly all clinical trials of myocardial reperfusion have excluded patients with a history of coronary artery bypass grafting. Furthermore, the only available data for the use of thrombolytic agents in this patient group consist of case reports of intracoronary thrombolytic agents ${ }^{3}$ and a small series of intravenous thrombolytic agents. ${ }^{4}$ There are no published data for the use of angioplasty or combined thrombolysis and angioplasty in patients with acute infarction after bypass surgery. Considering the increasing number of patients undergoing coronary artery bypass grafting and their propensity for future cardiac events, ${ }^{5}$ important questions regarding the optimal treatment strategy for prior coronary artery bypass patients come to bear. Accordingly, we reviewed our experience in the treatment of patients after coronary artery bypass surgery in the setting of evolving myocardial infarction.

Records from the University of Michigan Cardiac Catheterization Laboratory were reviewed from January 1, 1984, to December 30,1987, and a database of patients with a history of coronary artery bypass grafting and acute myocardial infarction was tabulated. Acute myocardial infarction was diagnosed when an episode of characteristic chest pain lasting $\geq 30$ minutes was associated with a transient, temporally appropriate increase of the total serum creatine phosphokinase above the upper limit of normal with myocardial isoenzyme fraction greater than twice normal. Data were compiled regarding the presence and type of standard electrocardiogram tracings at the time of infarction. Details of acute interventions, when performed, were accumulated, including those concerning the infarct-related vessel and whether or not the patient was treated with thrombolytic agents, direct angioplasty or a combination of the 2 . Status of the infarct-related vessel after intervention was also noted. Follow-up data regarding hospital discharge, repeat catheterization, exercise stress testing and the need for further intervention, including repeat bypass surgery, were also obtained.

Data are expressed as mean \pm 1 standard deviation. $A$ comparison of the efficacy of acute intervention as defined by infarct-related vessel patency after intervention was estimated by examining a cohort of patients who presented with acute myocardial infarction and had

From the Division of Cardiology, Department of Internal Medicine, University of Michigan Medical School, UHB1 F245, 1500 East Medical Center Drive, Ann Arbor, Michigan 48109-0022. Manuscript received September 1, 1989; revised manuscript received and accepted November 30, 1989.

no previous history of bypass surgery treated with thrombolysis and/or angioplasty in the Thrombolysis and Angioplasty in Myocardial Infarction-1 trial. ${ }^{6}$ Estimations of statistical significance were made using a chisquare test.

As listed in Table I, 40 patients met the criteria delineated previously during the time frame stated. The time since coronary artery bypass was $6 \pm 3.5$ years (range 2 months to 16 years). Age of the patients was 57 \pm 10 years (range 33 to 77 ); 31 of 40 were male $(72 \%)$. Although all patients presented with symptoms consistent with acute myocardial infarction and subsequently ruled in by enzymatic criteria, only 21 of 40 (53\%) had typical $S T$-segment elevation or new $Q$ waves. The remainder presented with ST depression or nonspecific electrocardiogram changes, thus not allowing localization of the site of myocardial infarction by these means. Thirty-five of the patients (88\%) underwent diagnostic cardiac catheterization within close temporal relation to the onset of their symptoms. Of these patients, the infarct-related vessel could be reliably identified in 26 (74\%); 12 were native vessel occlusions $(46 \%)$ and 14 were saphenous vein grafts (54\%). Left internal thoracic artery grafts were not present in any of our patients. Acute intervention was attempted in 20 of these patients in whom the infarct-related vessel could be ascertained. The time from onset of symptoms to intervention was 4 \pm 1 hours (range 2 to 6 ).

Intravenous thrombolysis was only used in $4(10 \%)$ of the patients $(100 \mathrm{mg}$ of recombinant tissue plasminogen activator in 2 cases, 1.5 million U of intravenous streptokinase in 1 case and 500,000 U of urokinase in 1 case) and was successful in establishing vessel patency in 3 (75\%). The infarct-related artery of the patient with unsuccessful reperfusion was a native right coronary artery. Direct coronary angioplasty of the infarct-related vessel was performed in 9 patients (23\%) and vessel patency was achieved in 7 (78\%). The 2 unsuccessful coronary angioplasties were in saphenous vein grafts, 1 to the left anterior descending artery and 1 to an obtuse marginal branch. Combined angioplasty and thrombolytic therapy (intracoronary urokinase or streptokinase) was performed in 7 patients and resulted in reperfusion in 6 (86\%). The unsuccessful combined therapy was in a patient with a native right coronary as the infarct-related vessel. Angiographically demonstrable embolic complications were not noted. The total success rate of all acute interventions in establishing infarct-related vessel patency was 16 of 20 (80\%). A similarly treated cohort of patients obtained from the Thrombolysis and Angioplasty in Myocardial Infarction trials revealed a reperfusion rate of $92 \%$ in 855 patients with native coronary artery thrombosis receiving thrombolysis and/or coronary angioplasty $(p=0.06)$. Of the patients not undergoing acute percutaneous intervention in this study, 2 had 


\begin{tabular}{|c|c|c|c|c|c|c|c|}
\hline $\begin{array}{l}\text { Age (yrs), } \\
\text { Sex }\end{array}$ & $\begin{array}{l}\text { Years } \\
\text { After } \\
\text { CABG }\end{array}$ & $\begin{array}{l}\text { Location } \\
\text { of } \mathrm{MI}\end{array}$ & Treatment & $\begin{array}{l}\text { ECG } \\
\text { Localization }\end{array}$ & $\begin{array}{l}\text { Infarct } \\
\text { Conduit }\end{array}$ & $\begin{array}{l}\text { Patent } \\
\text { Conduit }\end{array}$ & Outcome \\
\hline $57, M$ & 6 & NQMI & Medical & Undetermined & Undetermined & - & Negative ETT \\
\hline $51, M$ & 5 & Anterior & PTCA & Anterior & SVG-LAD & + & Died \\
\hline $46, \mathrm{~F}$ & 0.5 & Inferior & Medical & Inferior & Right & - & Patent artery at $1 \mathrm{yr}$ \\
\hline $55, \mathrm{~F}$ & 1 & NQMI & CABG & Undetermined & Undetermined & - & Negative ETT \\
\hline $70, \mathrm{M}$ & 16 & NQMI & Medical & Inferior & Undetermined & - & Unknown \\
\hline $56, \mathrm{M}$ & 7 & Inferior & Medical & Inferior & OM & - & Negative ETT \\
\hline $43, \mathrm{~F}$ & 2 & Inferior & Combined & Inferior & Right & 0 & PTCA of nonIRV \\
\hline $57, M$ & 5 & NQMI & Medical & Undetermined & Undetermined & - & Died \\
\hline $43, M$ & 2 & Inferior & Combined & Inferior & Right & + & Patent artery at 6 months \\
\hline $51, M$ & 5 & Inferior & Combined & Inferior & SVG-RCA & + & Restenosed IRV, unsuccessful PTCA \\
\hline $47, \mathrm{~F}$ & 5 & Inferior & Combined & Inferior & Right & + & Restenosed IRV, successful PTCA \\
\hline $58, M$ & 9 & NQMI & Medical & Undetermined & Undetermined & - & Died \\
\hline $58, \mathrm{M}$ & 3 & Inferior & Medical & Inferior & SVG Right & - & Negative ETT \\
\hline $45, F$ & 11 & Inferior & Thrombolysis & Inferior & SVG Right & + & PTCA of Residual Stenosis \\
\hline $76, \mathrm{M}$ & 3 & NQMI & Medical & Undetermined & Undetermined & - & Negative ETT \\
\hline $61, M$ & 6 & NQMI & Medical & Undetermined & LAD & - & Delayed PTCA of IRV \\
\hline $56, M$ & 6 & Inferior & Combined & Inferior & SVG-OM & + & Repeat CABG \\
\hline $55, F$ & 8 & NQMI & PTCA & Undetermined & SVG-OM & 0 & Died 3 months later \\
\hline $56, M$ & 8 & NQMI & PTCA & Undetermined & SVG-LC & + & Repeat CABG \\
\hline $58, \mathrm{~F}$ & 5 & NQMI & CABG & Undetermined & Undetermined & - & Died \\
\hline $67, M$ & 13 & Inferior & Medical & Inferior & SVG-Right & - & Unsuccessful PTCA of IRV \\
\hline $56, M$ & 11 & Inferior & Thrombolysis & Inferior & SVG-OM & + & Delayed PTCA of IRV \\
\hline $65, F$ & 6 & Anterior & Thrombolysis & Anterior & SVG-LAD & + & IRV patent, negative ETT \\
\hline $56, M$ & 4 & NQMI & Medical & Undetermined & LC & - & Repeat CABG \\
\hline $60, M$ & 6 & Inferior & Combined & Inferior & Right & + & Patent IRV at repeat angiography \\
\hline 19, M & 3 & NQMI & PTCA & Undetermined & SVG-LAD & 0 & Repeat CABG \\
\hline $57, M$ & 6 & NQMI & PTCA & Undetermined & SVG-OM & + & Negative ETT \\
\hline $60, M$ & 6 & NQMI & PTCA & Undetermined & SVG-OM & + & Negative ETT \\
\hline $57, M$ & 10 & NQMI & Medical & Undetermined & Undetermined & -- & Repeat CABG \\
\hline $77, M$ & 10 & NQMI & Medical & Undetermined & Undetermined & - & Died 2 months later \\
\hline $62, M$ & 0.25 & Inferior & PTCA & Inferior & SVG-OM & + & Positive ETT, medical therapy \\
\hline $33, M$ & 0.1 & Inferior & PICA & Inferior & Right & + & Patent IRV at repeat angiography \\
\hline $75, \mathrm{~F}$ & 6 & NQMI & Medical & Undetermined & Undetermined & - & Died 3 months later \\
\hline $64, M$ & 11 & NQMI & Medical & Undetermined & Undetermined & - & Unknown \\
\hline $12, \mathrm{M}$ & 5 & NQMI & Medical & Undetermined & Undetermined & - & Negative ETT \\
\hline $44, M$ & 4 & Inferior & PTCA & Inferior & Right & + & Patent IRV at repeat angiography \\
\hline $62, M$ & 5 & Inferior & Combined & Inferior & Right & + & Negative ETT \\
\hline $61, M$ & 7 & NQMI & Medical & Undetermined & Undetermined & - & Died 4 months later \\
\hline $51, M$ & 6 & Inferior & Thrombolysis & Inferior & Right & 0 & Delayed PTCA of IRV \\
\hline $63, M$ & 10 & Inferior & Medical & Inferior & Undetermined & - & Died 3 months later \\
\hline
\end{tabular}

emergency repeat coronary artery bypass grafting and the remaining 18 were treated medically.

Four patients died in the hospital (10\%). Two of these patients had been treated medically; 1 died during emergency repeat coronary artery bypass surgery and the other died during acute coronary angioplasty (without combined thrombolysis). The intermediate-term postdischarge outcome was available in 38 of 40 patients. There were 4 deaths within the first 3 months, 3 in patients who had been treated medically and 1 by acute intervention with angioplasty only. Five patients had repeat coronary artery bypass grafting, 2 of whom had been treated medically, 2 by angioplasty only and 1 by combined thrombolysis and angioplasty. Eight patients had further revascularization by coronary angioplasty. Three of the 4 patients treated by thrombolysis alone had angioplasty of a residual stenosis of the infarctrelated vessel. Two patients from the group initially treated with combined angioplasty and thrombolysis had restenosis of the infarct-related artery of which one was successfully dilated. One other patient from the combined treatment group had a delayed angioplasty of a noninfarct-related artery. Two patients in the medically treated group had delayed angioplasties; 1 was successful. Thus, 8 of 20 patients (40\%) initially treated with acute intervention went on to have successful revascularization procedures after their acute infarct; 1 was lost to follow-up and 1 died. The remainder had patent infarct-related arteries at recatheterization or were asymptomatic clinically.

The number of patients undergoing coronary artery bypass grafting with saphenous vein grafts has been steadily increasing. ${ }^{7}$ Considering that the rate of late graft occlusion is approximately $4 \% /$ year $^{8}$ and the yearly rate of myocardial infarction after coronary artery bypass surgery is approximately $3 \%,{ }^{9}$ the number of patients at risk for these events continues to increase. Thus, this group of patients represents an increasing proportion of cases of acute myocardial infarction that may benefit from acute intervention. However, the experience on the 
use of thrombolytic agents or angioplasty in these patients remains very limited.

This study reports our experience in patients after coronary artery bypass grafting in the setting of acute myocardial infarction. Although the number of patients available for review is small when compared to large scale clinical trials, it represents a large series of such patients reported to date. Furthermore, we report all such patients presenting to our institution regardless of whether or not an intervention was performed.

We noted a limited ability of the standard electrocardiogram to corroborate acute myocardial infarction and aid in ability to determine the infarct area. The preponderance of non-Q-wave myocardial infarcts in our study probably relates to either the finding that the infarctrelated vessel is less likely to be a main epicardial artery ${ }^{10}$ or to the presence of collaterals. Thus, such infarcts are usually smaller in postcoronary artery bypass surgery patients. ${ }^{11}$ This observation may impede the ability to promptly intervene in these patients when they present with acute myocardial infarction.

Furthermore, even with angiography the infarctrelated vessel could not be reliably identified in a fairly large proportion of our patients. This phenomenon was due to the presence of $>1$ vessel occlusion or multiple discordant wall motion abnormalities. With our concern over patient safety intervention with direct angioplasty or intracoronary thrombolysis was not possible in this group.

However, in our patients in whom the infarct-related vessel could be ascertained and acute intervention was performed, the results as assessed by vessel patency compared less favorably with a cohort of patients who never had bypass surgery. Although the lesions encountered in these patients may have been somewhat more "resistant" to thrombolytic therapy or angioplasty, there was yet a high degree of success. We did not encounter overt angiographic evidence of embolic complications as reported by others. ${ }^{12}$ Furthermore, more definitive revascularization with redo surgery was then possible in many of these patients at a later date. The limited number of patients in our study preclude recommendations as to the general treatment of such patients. However, based on this experience acute intervention in this setting is a viable option, albeit with a decreased reperfusion success rate, but with a potentially positive impact on the prognosis of these patients. There appears to be no legitimate reason to exclude this important group of patients from prospective reperfusion trials.

1. White HD, Norris RM, Brown MA, Takayama M, Maslowski A, Bass NM, Ormiston JA. Whitlock T. Effect of intravenous streptokinase on left ventricular function and early survival after acute myocardial infarction. $N$ Engl $J$ Med 1987:317:850-855.

2. Gruppo Italiano per lo Studio della Streptochinasi nell'Infarto Miocardico (GISSI). Effectiveness of intravenous thrombolytic treatment in acute myocardial infarction. Lancet 1986:1:397-401.

3. Pezzella AT, Svinarich JT, Davis RC, Jr, Ehrich D, Esente P. Successful early streptokinase thrombolysis of aortocoronary vein grafts. Ann Thorac Surg 1986:42:213-215.

4. Kleiman NS, Berman DA, Gaston WR, Cashion WR, Roberts R. Early intravenous thrombolytic therapy for acutc myocardial infarction in patients with prior coronary artery bypass grafts. Am J Cardiol 1989;63:102-104.

5. Wiseman A, Waters DD, Walling A, Pelletier GB, Roy D, Theroux P. Longterm prognosis after myocardial infarction in patients with previous coronary artery bypass surgery. $J A C C$ 1988:12:873-880.

6. Topol EJ, Califf RM, George BS, Kereiakes DJ, Abbottsmith CW, Candela RJ, Lee KL, Pitt B, Stack RS, O'Neill WW, and the Thrombolysis and Angioplasty in Myocardial Infarction Study Group. A randomized trial of immediate versus delayed elective angioplasty after intravenous tissue plasminogen activator in acute myocardial infarction. $N$ Engl $J$ Med 1987;317;581-588.

7. Loop FD, Lytle BW, Gill CC, Golding LAR, Cosgrove DM, Taylor PC. Trends in selection and results of coronary artery reoperations. Ann Thorac Surg 1983,36:380-388.

8. Campeau L, Lesperance J, Bourassa MG. Natural history of saphenuus vein aortocoronary bypass grafts. Mod Concepts Cardiovasc Dis 1984;53:59-63.

9. Coronary Artery Surgery Study (CASS) Principal Investigators and Their Associates. A randomized trial of coronary artery bypass. Quality of life in patients randomly assigned to treatment groups. Circulation 1983,68:951-956. 10. Crean PA, Waters DD, Bosch $X$, Pelletier GB, Roy D, Theroux $P$. Angiographic findings after myocardial infarction in patients with previous bypass surgery: explanations for smaller infarcts in this group compared with control patients. Circulation 1985;71:693-698.

11. Waters DD, Pelletier GB, Hache M, Theroux P, Campeau L. Myocardial infarction in patients with previous coronary artery bypass surgery. JACC 1984,3:909-915.

12. De Feyter PJ, Serruys P, van den Brand.M, Meester H, Beatt K, Suryapranata $H$. Percutaneous transluminal angioplasty of a totally occluded venous bypass graft: a challenge that should be resisted. Am J Cardiol 1989,64:88-90.

\title{
Effects of Verapamil on the Anaerobic Threshold and Peak Oxygen Consumption in Effort Angina Pectoris
}

\author{
Andrew Thomson, MB, PhD, FRACP, and David T. Kelly, MB, FRACP
}

$\mathbf{T}$ he anaerobic threshold is the submaximal level of exertion above which lactic acid progressively accumulates in the blood and fatigue progressively increases during incremental exercise. ${ }^{1,2}$ The anaerobic threshold is a useful clinical measurement of submaximal exercise performance in normal subjects ${ }^{1-3}$ and in patients with congestive heart failure, ${ }^{4}$ angina pectoris ${ }^{5}$ and valvular regurgitation, ${ }^{6}$ and has been used to assess drug interventions. ${ }^{7}$ In patients with effort angina, ST-segment depres-

From the Hallstrom Institute of Cardiology, Royal Prince Alfred Hospital, Sydney, and the Department of Cardiology, Royal Hobart Hospital, GPO Box 1061L, Hobart 7001, Australia. This study was supported in part by the National Health and Medical Research Council of Australia, Canberra, ACT, Australia. Manuscript received July 20 , 1989; revised manuscript received November 15,1989 , and accepted December 4. sion is reduced and exercise time increased after calcium antagonists. $^{8,9}$ If relief of myocardial ischemia by verapamil allows an improvement in peak oxygen consumption $\left(\mathrm{VO}_{2 \text { peak }}\right)$, there may also be an improvement in oxygen metabolism by exercising muscle and the anaerobic threshold may increase, delaying the onset of fatigue. This study determines whether verapamil alters the oxygen consumption $\left(\mathrm{VO}_{2}\right)$ at the anaerobic threshold, or the perception of leg fatigue in patients with effort angina pectoris.

Sixteen patients with stable exertional angina pectoris and positive exercise tests (Bruce protocol with at least 1 -mm horizontal ST-segment depression) entered the study. No patient had chronic lung disease, valvular regurgitation, clinical heart failure or peripheral vascular disease. All patients gave written informed consent 